\title{
Bisnis Online: Upaya Peningkatan Pendapatan Perempuan Penerima PKH di Tengah Pandemi Covid-19
}

\author{
Nazeli Adnan', Sri Andaiyani*2, Feny Marissa ${ }^{3}$, Fera Widyanata4, Zulkarnain Ishak ${ }^{5}$ \\ 1,2,3,4,5 Jurusan Ekonomi Pembangunan, Fakultas Ekonomi, Universitas Sriwijaya \\ *e-mail: sriandaiyani@fe.unsri.ac.id
}

\begin{abstract}
The Covid pandemic not only has an impact on the health aspect but also the economic aspect of the community, including the recipients of the Family Hope Program (PKH). Through the power of housewives who are considered to be able to help the family economy, online business is a new trend today. Therefore, the Sriwijaya University community service activity team provided training related to how to manage an online business. This activity was carried out on November 9, 2020 offline while adhering to health protocols. This training was attended by 40 PKH beneficiaries in Ilir Barat II District, Palembang City, South Sumatra Province. The methods used are presentation, tutoria and discussion. The results showed that 80 percent of participants understood the importance of online promotion through social media. The understanding related to the benefits of social media, types of social media, and downloading applications is quite good where the percentage obtained is above 70 percent. However, understanding regarding the use of Instagram is still lacking where the results only reach $65 \%$.
\end{abstract}

Keywords: Family Hope Program, Online Shop, Online Business, Women Entrepreneurs

\begin{abstract}
Abstrak
Pandemi covid tidak hanya berpengaruh terhadap kesehatan tetapi juga ekonomi masyarakat tak terkecuali penerima program keluarga harapan (PKH). Melalui kekuatan ibu rumah tangga yang dianggap mampu membantu perekonomian keluarga, bisnis online menjadi trend baru saat ini. Oleh karena itu, tim kegiatan pengabdian masyarakat Universitas Sriwijaya memberikan pelatihan terkait cara mengelola bisnis online. Kegiatan ini dilaksanakan pada tanggal 9 November 2020 secara offline dengan tetap memperhatikan protokol kesehatan. Pelatihan ini diikuti oleh 40 penerima manfaat PKH di Kecamatan Ilir Barat II, Kota Palembang, Provinsi SUMSEL. Metode yang digunakan adalah presentasi, tutorial dan diskusi. Hasil penelitian menunjukkan bahwa 80 persen peserta memahami pentingnya promosi online melalui media sosial. Pemahaman terkait manfaat media sosial, jenis media sosial, dan pengunduhan aplikasi cukup baik dimana persentase yang diperoleh di atas 70 persen. Namun pemahaman mengenai penggunaan Instagram masih kurang dimana hasilnya hanya mencapai $65 \%$.
\end{abstract}

Kata kunci: Program Keluarga Harapan, Toko Online, Bisnis Online, Pengusaha Wanita

\section{PENDAHULUAN}

Pandemi Covid-19 mempengaruhi hampir seluruh aspek kehidupan. Indonesia yang didominasi oleh masyarakat pra sejahtera juga terdampak baik dari segi kesehatan maupun hilangnya pekerjaan. Penerima manfaat PKH ini diharapkan mampu bertahan hidup dimasamasa sulit seperti ini. Melalui kekuatan ibu rumah tangga yang dianggap dapat membantu ekonomi keluarga, bisnis online menjadi sebuah trend baru saat ini.

Tren berbelanja online dimasa pandemi ini tentunya dapat dijadikan peluang bagi masyarakat khususnya penerima manfaat PKH. Disisi lain, perhatian pemerintah tidak hanya pada perubahan perilaku keluarga tetapi juga pada peningkatan ekonomi. Merintis usaha berbasis online menjadi salah satu solusi yang dapat dilakukan oleh masyarakat guna memperoleh tambahan pemasukan. Tercatat tren peningkatan permintaan melalui e-commerce maupun layanan antar online terus menunjukkan peningkatan. Rendahnya motivasi dan pengetahuan para penerima manfaat PKH menjadikan mereka lebih pasif dan tidak dapat memanfaatkan peluang yang ada untuk meningkatka ekonomi keluarga. 
Pada kegiatan ini, target peserta merupakan para penerima manfaat PKH khususnya ibuibu. Pengusaha di Indonesia masih didominasi oleh laki-laki sehingga masih dirasa perlu untuk memotivasi perempuan-perempuan Indonesia untuk lebih mandiri dalam keuangan. Selain itu juga, Siswanto (2009) menyatakan keterampilan perempuan dalam memanfaatkan teknologi komunikasi diharapkan meningkat seiring dengan perkembangan zaman. Peningkatan pengetahuan dan keahlian dalam pemanfaatan teknologi informasi dapat dikembangkan melalui pelatihan, pendampingan dan workshop penggunaan teknis media sosial.

Program Keluarga Harapan (PKH) merupakan bantuan langsung sosial dari pemerintah untuk rumah tangga yang tergolong miskin. Penerima manfaat PKH akan diberikan bantuan uang tunai yang dapat dibelanjakan oleh mereka. Program ini merupakan usaha pemerintah Indonesia dalam menangulangi kemiskinan. Melalui $\mathrm{PKH}$, rumah tangga miskin diharapkan mendapatkan akses serta mampu memanfaatkan fasilitas pelayanan sosial dasar seperti kesehatan, pendidikan, pangan dan gizi, perawatan dan pendampingan, dan berbagai program perlindungan sosial lainnya yang menjadi program komplementer keberlanjutan. Oleh kareba itu, keluarga penerima manfaat PKH ini mendapatkan pendampingan khusus dari fasilitator yang ditunjuk oleh kementrian sosial.

Sejak adanya Program PKH ini, pemerintah memberikan layanan pendamping bagi para penerima PKH. Pendamping PKH mendapat bekal materi dan tata cara komunikasi yang baik. Pada pelatihan ini diberikan materi terkait PKH dan cara berkomunikasi dengan masyarakat. Menurut Habibullah (2011), pelatihan ini diharapkan mampu menambah wawasan serta keterampilan penerima manfaat PKH. Namun, pada praktiknya, Samosir (2013) yang menujukan bahwa pendamping dalam PKH tidak berjalan efektif karena terdapat 77.11 persen rumah tangga miskin menyatakan bahwa pendamping tidak mempengaruhi secara signifikan pada penerima PKH ini.

Munculnya pandemi covid-19 ini ternyata menggerus ekonomi berbagai lapisan masyarakat, tak terkecuali para penerima manfaat PKH. Dampak Covid-19 juga menurunkan produktifitas bagi UMKM (Usaha Mikro Kecil Menengah) di Berbagai Wilayah.Namun, disini tim pengabdian fakultas ekonomi melihat ada ruang bagi para akademisi untuk mengajak para penerima manfaat PKH untuk meningkatkan taraf hidup mereka secara mandiri. Oleh karena itu. Hal ini didukung oleh Handajani, Akram, Furkan, \& Rifa'i (2019) \& Rahman \& Nurdian (2021) yang menyatakan media sosial dapat menjadi wadah promosi bagi para pelaku bisnis. Perkembangan teknologi informasi ini menjadi dasar bagi terciptanya peluang-peluang bisnis di kalangan perempuan. Berdasarkan masalah di atas, Tim Pengabdian Kepada Masyarakat Fakultas Ekonomi Universitas Sriwijaya mengajak Ibu-ibu penerima PKH untuk menengok peluang bisnis yang menguntungkan di masa pandemi ini dan mengajak beberapa Ibu-Rumah Tangga yang sudah memiliki usaha untuk membuat usahanya menjadi menarik, dengan memberikan sosialisai mengenai tips-tips mendirikan bisnis dan menjalankan bisnis, bagaimana cara promosi yang efektif serta membantu mambuatkan konten produk di media sosial instagram.

\section{METODE}

Khalayak sasaran yang dipilih adalah para penerima manfaat Program Keluarga Harapan (PKH) sebanyak 40 orang di Kecamatan Ilir Barat II Kota Palembang. Metode pelaksanaan kegiatan pengabdian ini adalah pelatihan. Adapun rangkaian kegiatan yang diberikan adalah presentasi, tutorial, dan diskusi. Pertama, tim pelaksana memberikan sosialisai mengenai tipstips mendirikan bisnis dan mengembangkan bisnis, bagaimana cara promosi yang efektif dan penggunaan sosial media (instagram) dalam berbisnis. Selanjutnya, Peserta diberikan pelatihan cara membuat media sosial sebagai alternative cara pemasaran produk. Peserta diajak menggunakan media sosial instagram. Peserta diminta untuk mengunduh salah satu media online sebagai alternative pemasaran produk (Gambar 1). Terakhir, peserta pelatihan dapat mengonsultasikan kendala-kendala yang dihadapi selama berbisnis online. 


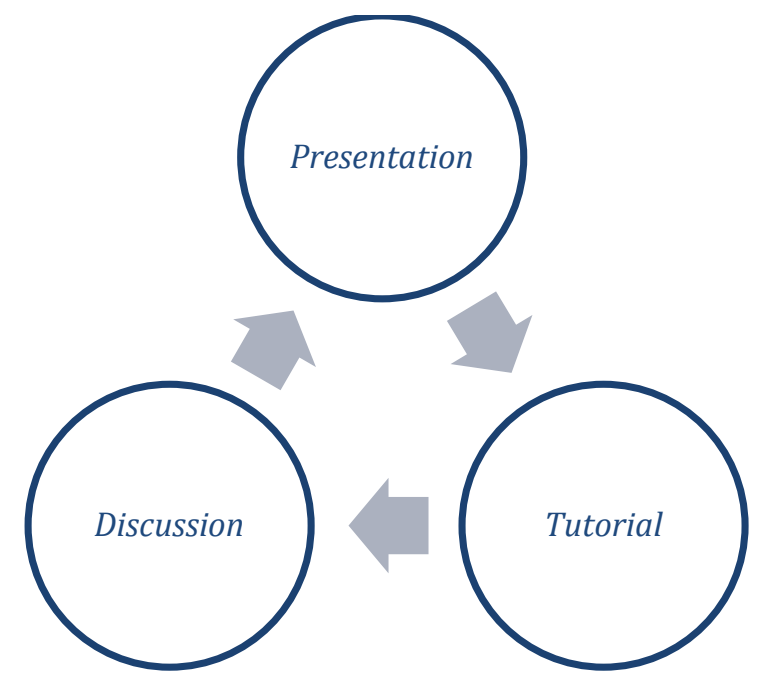

Gambar 1. Metode Pelaksanaan

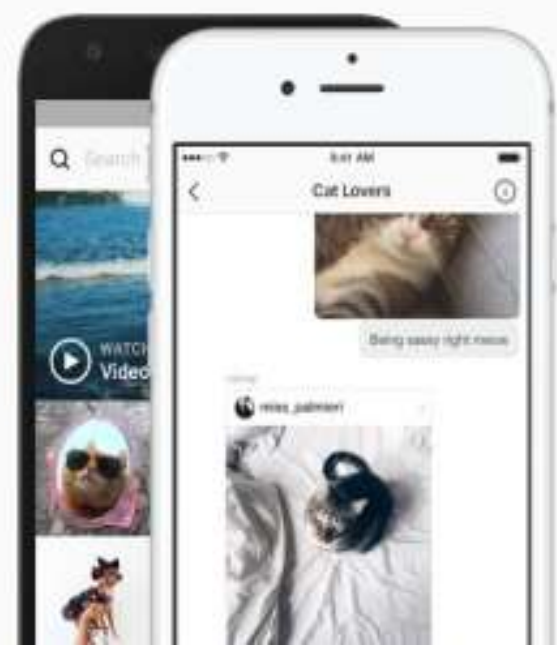

\section{Instagram}

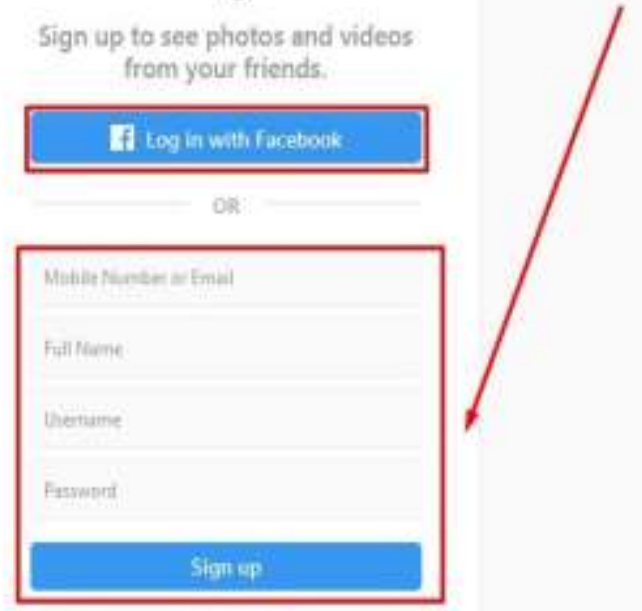

Gambar 2. Akun Instagram

\section{HASIL DAN PEMBAHASAN}

Kegiatan pengabdian kepada masyarakat Universitas Sriwijaya telah dilakukan pada tanggal 09 November 2020 secara offline dengan tetap mematuhi protokol kesehatan. Pelatihan ini diikuti oleh 40 penerima manfaat PKH di Kecamatan Ilir Barat II Kota Palembang Provinsi Sumatera Selatan. Peserta pelatihan berasal dari kelurahan 29 ilir, Kelurahan 30 Ilir, Kelurahan Kemang Manis dan Kelurahan 35 Ilir. 75 \% penerima manfaat PKH memiliki warung-warung sederhana seperti warung kelontong, warung kopi, warung gorengan dan lain-lain. Ada pula beberapa peserta yang memiliki usaha kerajinan tangan khas kota palembang berupa souvernir. Pada saat pengabdian masyarakat dilakukan, tim pelaksana memberikan penjelasan terkait bisnis online yang bisa dijalankan dari rumah. Narasumber pertama, Bapak Nazeli Adnan, 
memberikan pengetahuan terkait dengan pentingnya promosi online dan maanfaatnya bagi keberlangsungan usaha di tengah pandemi covid 19. Selain itu, kegiatan pengabdian ini memberikan tutorial bagaimana cara menggunakan aplikasi bisnis online yang paling sederhana bagi masyarakat awam seperti whatsapp dan instagram (Gambar 3b).

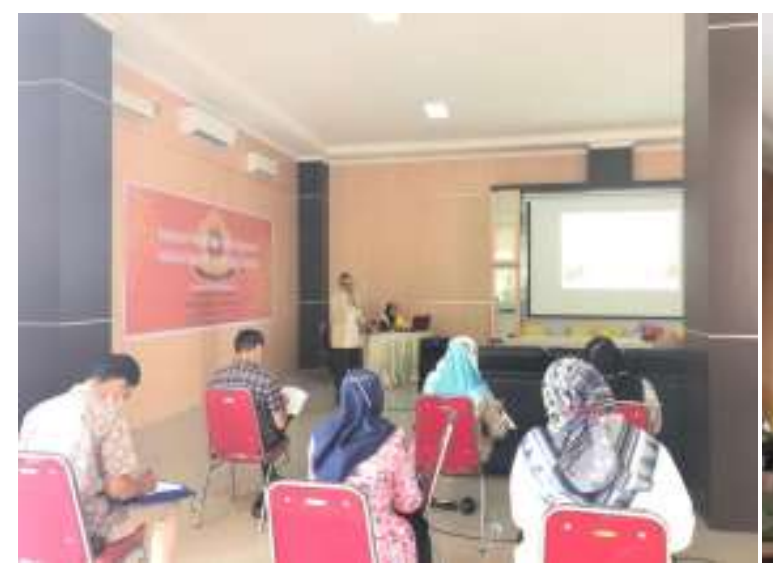

(a)

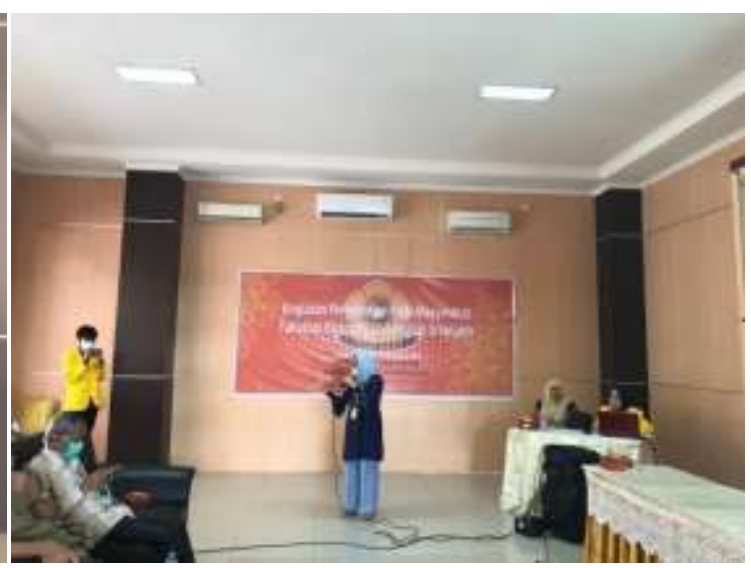

(b)

Gambar 3. Penyampaian Materi (a) Narasumber 1 (b) Narasumber 2

Tim pelaksana pengabdian kepada masyarakat Universitas Sriwjaya memandu langsung ibu-ibu rumah tangga penerima PKH untuk dapat menjalankan aplikasi instagram dan whatsapp. Para peserta pelatihan diarahkan untuk menggunakan aplikasi whatsapp dan instagram sebagai media promosi yang dapat digunakan dalam berbisnis online. Bagi peserta yang belum memiliki aplikasi ini dipandu oleh tim untuk membuat akun instagram dan whatsapp. Setelah itu, tim pelaksana membagikan kuisioner dan evaluasi kepada para peserta pelatihan.

Berdasarkan hasil olah data kuisioner yang telah diisi oleh para peserta, kendala yang kerap dihadapi oleh para peserta adalah belum optimalnya pemasaran, keterbatasan modal dan persaingan yang semakin ketat. Sekitar 20 persen peserta masih kekurangan modal untuk menjalankan usahanya bahkan 25 peserta yang belum memiliki usaha masih terkendala oleh modal. Rendahnya literasi keuangan para peserta mengindikasikan kurangnya pengetahuan terkait pinjaman modal dari perbankan. Selain itu, kapasitas usaha dan tidak adanya jaminan yang menyebabkan peserta pelatihan tidak berani meminjam modal produktif di perbankan. Akibatnya, peserta pelatihan meminjam dana pada rentenir. Sedangkan, dana yang peserta peroleh dari PKH dianggap masih tidak cukup untuk memenuhi kebutuhan modal usaha.

Permasalahan kedua adalah belum optimalnya pemasaran produk. Selama ini, media promosi produk hanya dari mulut ke mulut. Sekitar 35 persen dari peserta yang memiliki usaha yang meggunakan media sosial sebagai sarana promosi, seperti facebook, instagram dan whatsapp. Sedangan peserta yang memiliki akun e-commerce belum ada. Peserta yang memiliki akun instagram hanya 25 orang dari 40 orang. 17 orang diantaranya masih menggunakan instagram pribadi sebagai media promosi. Artinya, ibu-ibu penerima manfaat PKH ini masih menggabungkan akun sosial media pribadi dengan akun sosial media bisnis.

Tim pelaksana pengabdian kepada masyarakat memberikan pelatihan bagaimana memanfaatkan media sosial dengan baik untuk menjalankan bisnis dari rumah. Dengan demikian, pendampingan dalam membuat akun instagram bagi yang belum memiliki akun tersebut sangat diperlukan. Oleh karena itu, tim pelaksana memberikan pendampingan langsung kepada para peserta untuk membuat akun instagram. Selanjutnya, tim pelaksana memberikan tutorial bagaimana mengaplikasi akun instagram untuk berjualan online. Konten instagram 
sangat penting agar menjaga pelayanan kepada konsumen tetap optimal. Gambar 4 di atas menunjukkan contoh-contoh akun instagram yang mulai aktif mempromosikan produknya. Tim pelaksana memberikan contoh konten-konten yang menarik kepada peserta. Para peserta juga diajarkan bagaimana cara membuat konten foto dan video produk yang baik dan menarik konsumen.

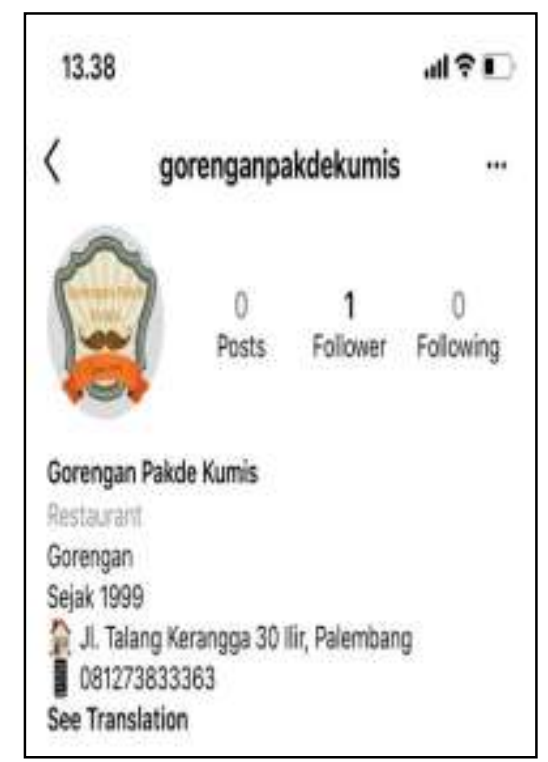

Gambar 4. Contoh Pembuatan Akun Instagram Baru

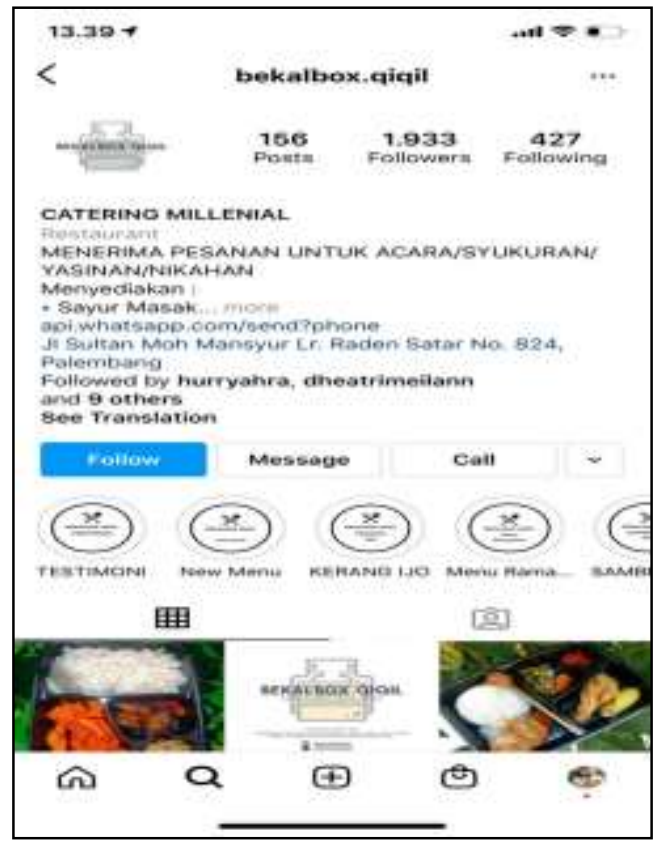

(a)

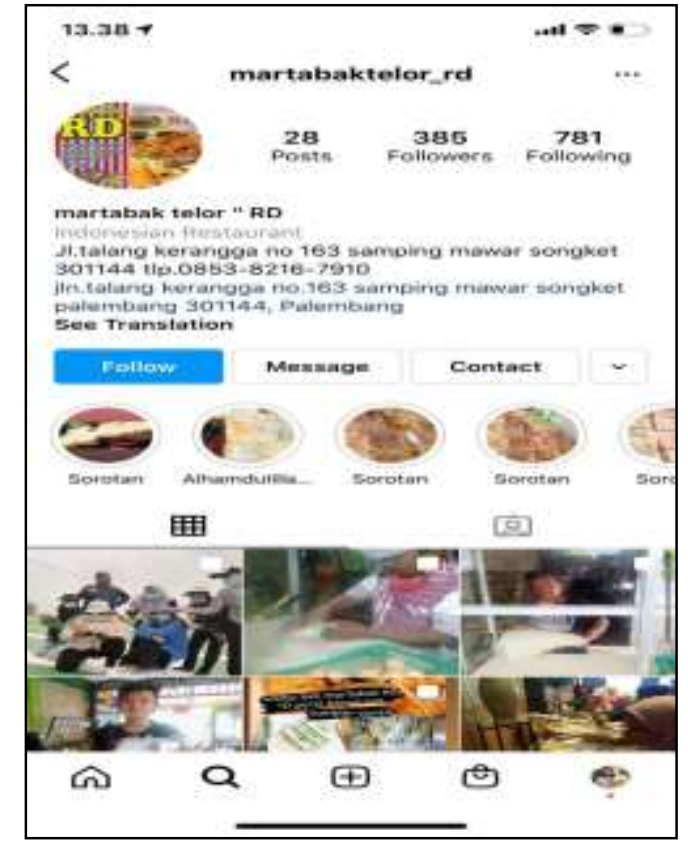

(b)

Gambar 5. Bisnis Online Peserta melalui Instagram (a) Bisnis Catering (b) Bisnis Martabak

Perempuan memiliki potensi dalam membantu keuangan rumah tangga terutama bagi masyarakat menengah ke bawah. Pada rumah tangga golongan menengah ke bawah, perempuan terjun langsung dalam pasar tenaga kerja untuk menambah pendapatan rumah tangga yang belum mencukupi kebutuhan. Menurut Haryanto (2008) pendapatan perempuan menjadi salah 
satu sumber pendapatan keluarga yang digunakan untuk memenuhi kebutuhan prime dan sekunder. Oleh karena itu, kegiatan yang dilakukan ini dianggap tepat sasaran bagi para peserta. Materi yang disampaikan telah sesuai dengan kebutuhan para peserta yang minim ilmu terkait pemanfaatan bisnis online dan media sosial.

Berdasarkan hasil evaluasi diperoleh bahwa 80 persen peserta telah memahami pentingnya promosi online melalui sosial media. Pemasaran melalui social media dipercaya dapat meningkatkan hasil penjualan usaha masayarakat (Rahman \& Nurdian, 2021). Pemahaman terkait manfaat media sosial, jenis-jenis media sosial, dan mengunduh aplikasi sudah cukup baik dimana presentase yang diperoleh di atas 70 persen. Namun, pemahaman terkait penggunaan instagram masih kurang dimana hasilnya hanya mencapai 65\%. Hal ini berkaitan dengan fitur-fitur yang ada di instagram, pembuatan konten dan tampilan instagram yang menarik. Berdasarkan tabel 1. Rata-rata pemahaman peserta sebesar 74 persen diatas target capaian 70 persen.

Tabel 1. Evaluasi Kegiatan

\begin{tabular}{clcc}
\hline No & Poin Pertanyaan & Kode & Persentase \\
\hline 1 & Pemahaman terkait pentingnya media promosi online & P1 & $80 \%$ \\
2 & Pemahaman terkait manfaat pemasaran online & P2 & $71 \%$ \\
3 & Pemahaman terkait akun media social & P3 & $69 \%$ \\
4 & $\begin{array}{l}\text { Pemahaman jenis-jenis media social } \\
5\end{array}$ & Pemahaman dalam mengunduh aplikasi instagram & $82 \%$ \\
& $\begin{array}{l}\text { Pan whatsApp } \\
6\end{array}$ & $77 \%$ \\
& $\begin{array}{l}\text { Pemahaman cara mengaplkasikan whatsApp dan } \\
\text { instagram }\end{array}$ & P6 & $65 \%$ \\
\hline
\end{tabular}

Sumber: Data Diolah, 2020

Berdasarkan hasil analisis, pengetahuan dan keterampilan dalam mengelola bisnis sangat diperlukan agar usaha meraka mendapat keuntungan maksimal. hal tersebut diidukung oleh hasil penelitian Idrus, Pauzi, \& Munir (2014) menunjukkan bahwa Program Kewirausahaan Wanita akan membantu meningkatkan produktivitas dan profitabilitas usaha mereka. Keterampilan dalam mempromosikan produk juga merupakan hal penting yang perlu dipelajari.

Jaringan sosial dapat meningkatkan peluang bisnis perempuan khusunya para penerima manfaat PKH. Pengetahuan dalam memanfaatkan media sosial dalam berbisnis sangat penting untuk mengembangkan usaha mereka. Menurut Yusuff, Abu Bakar, \& Ahmad (2016) menganggap promosi di media sosial dapat mengurai biaya modal. Media sosial membantu wirausahawan dalam mengakses informasi, sumber daya, dan peluang yang berharga.

Di Indonesia, ada trend yang berkembang untuk membuka usaha melalui media sosial, khususnya oleh kaum perempuan (Melissa, Hamidati, \& Saraswati, 2013); (Lestanata, Pratama, \& Zitri, 2021). Ada banyak alasan yang menjelaskan tren ini, alasan utamanya adalah fleksibilitas yang diberikannya pada bisnis, memungkinkan transaksi dilakukan dari mana saja, termasuk rumah sendiri. Oleh karena itu, kegiatan pengabdiaan ini mengajak peserta memanfaatkan bisnis online ini dengan mendampingi mereka menjadi wirausaha online. Para penerima manfaat PKH dapat memanfaatkan modal sosial yang diperoleh melalui interaksi media sosial sebagai awal dari toko online mereka. Kurangnya minat konsumen mengunjungi toko offline dapat menjadi tolak ukur pentingnya toko online ini. Selain itu, Promosi online telah terbukti dapat meningkatkan pendapatan pelaku usaha (Nina \& Matondang, 2021) 


\section{KESIMPULAN}

Kegiatan pengabdian kepada masyarakat Universitas Sriwijaya telah dilakukan pada tanggal 09 November 2020 secara offline dengan tetap mematuhi protokol kesehatan. Pelatihan ini diikuti oleh 40 penerima manfaat PKH di Kecamatan Ilir Barat II Kota Palembang Provinsi Sumatera Selatan. Peserta pelatihan berasal dari kelurahan 29 ilir, Kelurahan 30 Ilir, Kelurahan Kemang Manis dan Kelurahan 35 Ilir. 75 \% penerima manfaat PKH memiliki warung-warung sederhana seperti warung kelontong, warung kopi, warung gorengan dan lain-lain. Perempuan memiliki potensi dalam membantu keuangan rumah tangga terutama bagi masyarakat menengah ke bawah. 80 persen peserta telah memahami pentingnya promosi online melalui sosial media. Pemahaman terkait manfaat media sosial, jenis-jenis media sosial, dan mengunduh aplikasi sudah cukup baik dimana presentase yang diperoleh di atas 70 persen. Namun, pemahaman terkait penggunaan instagram masih kurang dimana hasilnya hanya mencapai $65 \%$. Dalam hal ini, pemerintah dapat memberikan pendampingan khusus kepada perempuan dalam mengembangkan usaha berbasis online. Adapun kontribusi praktis, lembaga keuangan dapat memberikan produk keuangan yang bermanfaat bagi perempuan pengusaha meningkatkan kinerja usahanya.

\section{UCAPAN TERIMA KASIH}

Terima kasih kepada Lembaga Penelitian dan Pengabdian kepada Masyarakat (LPPM) Universitas Sriwijaya yang telah memberikan bantuan dana Hibah Pengabdian sehingga kegiatan pengabdian kepada masyarakat dapat berjalan dengan baik.

\section{DAFTAR PUSTAKA}

Habibullah. (2011). Peran Pendamping Pada Program Keluarga Harapan di Kabupaten Karawang. Lnformasi, 16(02), 101-116.

Handajani, L., Akram, Furkan, L. M., \& Rifa'i, A. (2019). Penggunaan Pemasaran Digital Pada Usaha Home Industry Kopi Lombok di Desa Sigerongan Kabupaten Lombok Barat. Abdi Insani. https://doi.org/10.29303/abdiinsani.v6i3.267

Haryanto, S. (2008). Peran Aktif Wanita Dalam Peningkatan Pendapatan Rumah Tangga Miskin: Studi Kasus Pada Wanita Pemecah Batu Di Pucanganak Kecamatan Tugu Trenggalek *. Jurnal Ekonomi Pembangunan: Kajian Masalah Ekonomi Dan Pembangunan, 9(2), 216. https://doi.org/10.23917/jep.v9i2.1025

Idrus, S., Pauzi, N. M., \& Munir, Z. A. (2014). The Effectiveness of Training Model for Women Entrepreneurship Program. Procedia - Social and Behavioral Sciences, 129, 82-89. https://doi.org/10.1016/j.sbspro.2014.03.651

Lestanata, Y., Pratama, I. N., \& Zitri, I. (2021). Pendampingan Pelaku Usaha Mikro Kecil Dan Menengah Dalam Pemasaran Produk Secara Online Ditengah Covid-19 Di Desa Gumantar Kecamatan Kayangan Kabupaten Lombok Utara. TRANSFORMASI: JURNAL PENGABDIAN PADA MASYARAKAT. https://doi.org/10.31764/transformasi.v1i1.4505

Melissa, E., Hamidati, A., \& Saraswati, M. S. (2013). Social Media Empowerment: How Social Media Helps to Boost Women Entrepreneurship in Indonesian Urban Areas. IAFOR Journal of Media, Communication \& Film, 1(1), 77-90. https://doi.org/10.22492/ijmcf.1.1.06

Nina, M. A., \& Matondang, N. (2021). PKM Pemasaran Sosial Media Berbasis Mobile Dalam Rangka Membantu Keterbatasan Ruang Gerak Selama Pandemi Covid-19. Dinamisia : Jurnal Pengabdian Kepada Masyarakat. https://doi.org/10.31849/dinamisia.v5i2.4691

Rahman, T., \& Nurdian, Y. (2021a). Pendampingan Pemanfaatan Teknologi Digital Untuk Meningkatkan Pemasaran Toko Roti di Pabian Sumenep. DINAMISI: Jurnal Pengabdian Kepada Masyarakat, 5(3), 645-650.

Rahman, T., \& Nurdian, Y. (2021b). Pendampingan Pemanfaatan Teknologi Digital Untuk 
Meningkatkan Pemasaran Toko Roti Di Pabian Sumenep. Dinamisia: Jurnal Pengabdian Kepada Masyarakat. https://doi.org/10.31849/dinamisia.v5i3.4727

Samosir, A. P. (2013). Analisis Efektivitas Pelaksanaan Program Keluarga Harapan 2011. Jurnal Borneo Administrator, 9(2).

Siswanto, V. A. (2009). Studi Peran Perempuan Dalam Pengembangan Kota Pekalongan (Penelitian ini dibiayai oleh Kementrian Negara Pemberdayaan Perempuan) Victorianus Aries Siswanto. DINAMIKA INFORMATIKA, I(1), 70-77.

Yusuff, Y. Z., Abu Bakar, A. A., \& Ahmad, S. (2016). Microfinance and women entrepreneurs ' business performance: The mediating role of social capital. Journal for Studies in Management and Planning, 2(6), 82-96. 